\title{
Short term regulation of aldosterone secretion after stimulation and suppression experiments in mice
}

\author{
Ariadni Spyroglou, Jenny Manolopoulou, Sibylle Wagner ${ }^{1}$, Martin Bidlingmaier, \\ Martin Reincke and Felix Beuschlein \\ Department of Medicine, Endocrine Research, University Hospital Innenstadt, Ludwig Maximilians University, Ziemssenstr. 1, D-80336 Munich, Germany \\ ${ }^{1}$ Institute for Experimental Genetics, Helmholtz Center Munich, Neuherberg, 85746, Germany \\ (Correspondence should be addressed to F Beuschlein; Email: felix.beuschlein@med.uni-muenchen.de)
}

\begin{abstract}
Aldosterone is synthesized acutely from the zona glomerulosa cells upon stimulation by the renin-angiotensinaldosterone system. Several enzymes are involved in this steroidogenic process including the steroidogenic acute regulatory protein (StAR), P450 side chain cleavage enzyme (Cyp11a1), and aldosterone synthase (Cyp11b2) which has been demonstrated to be transcriptionally regulated by the nuclear transcription factors NGF1-B and Nurr1. We investigated the short time transcriptional regulation of these genes in wild-type mice at $10 \mathrm{~min}$ intervals for $1 \mathrm{~h}$ following application of $0.2 \mathrm{nmol}$ angiotensin II (ANGII) or sodium chloride in comparison sham injections. Using real-time PCR a fast upregulation of adrenal Cyp $11 \mathrm{~b} 2$ expression ( $53 \pm 5 \%$ increase over baseline) could be observed 10 min after sham injection which was accompanied by a transient increase in aldosterone secretion while StAR and Cyp11a1 upregulation was delayed and more sustained. ANGII caused an increase of StAR and Cyp11a1 expression similar to that observed after sham injection while Cyp $11 \mathrm{~b} 2$ upregulation was more pronounced (10 $\mathrm{min}, 236 \pm 39 \%)$ and reflected ANGIl induced stimulation of aldosterone output. Sodium challenge was followed by a sustained reduction of all three genes examined (Cyp11b2, $20 \mathrm{~min},-63 \pm 6 \%$ ) which was accompanied by a significant suppression of aldosterone secretion detectable after 60 min. While increases in NGF1-B mRNA levels were similar between the treatment groups, Nurr1 expression levels were induced only upon ANGII administration. These data suggest that acute regulation of aldosterone synthesis is accompanied by fast transcriptional modulation of steroidogenic enzymes and transcription factors that are likely to be involved in aldosterone secretion.
\end{abstract}

Journal of Molecular Endocrinology (2009) 42, 407-413

\section{Introduction}

Owing to their highly lipophilic structure, steroids including aldosterone cannot be stored in substantial quantities within the adrenal cortex but have to be synthesized on demand. Thus, rapid regulation of steroid synthesis is of particular importance to maintain homeostasis upon acute stimuli. Early on it had been demonstrated that the acute stimulation of glucocorticoid output from the adrenal gland by ACTH is sensitive to protein synthesis inhibitors (Ferguson 1963). Further studies identified steroidogenic acute regulatory protein $(S t A R)$ to initiate the cascade of steroid biosynthesis with the translocation of cholesterol from the outer to the inner mitochondrial membrane (Black et al. 1994, Clark et al. 1994, Spat \& Hunyady 2004). StAR expression is enhanced by ACTH and $\mathrm{Ca}^{2+}$ mediated stimuli such as angiotensin II (ANGII) and potassium (Spat \& Hunyady 2004). Upon stimulation StAR mRNA and protein levels are acutely induced via cAMP mediated mechanisms that result in the increase of StAR transcription and mRNA stability (Caron et al. 1997). Other transcription factors regulating long term StAR expression include steroidogenic factor 1 (SF-1), C/EBPs and putatively Sp1 (Reinhart et al. 1999). Furthermore, the transcriptional effect of ANGII involves the activation of ERK1/2 which represses DAX-1, a transcription factor known to inhibit SF-1 dependent transcription of StAR (Gummow et al. 2006). Moreover, post-translational modification including StAR phosphorylation on a threonine residue has been demonstrated to be required for acute induction of steroidogenesis (Stocco \& Clark 1993, Stocco et al. 2005).

Conversion of cholesterol to pregnenolone is catalyzed by the cholesterol side-chain cleavage enzyme (Cyp11a1) and takes place at the matrix side of the inner mitochondrial membrane (Hum \& Miller 1993). Pregnenolone exits the mitochondria and is converted to progesterone by 3 - $\beta$-hydroxysteroid dehydrogenase in the microsomal compartment. Progesterone is then further hydroxylated to form 11-desoxycorticosterone by 21 hydroxylation (Otis \& Gallo-Payet 2007). The aldosterone synthase $(C y p 11 b 2)$ is required for the final 
steps of aldosterone synthesis through hydroxylation and 18-oxidation of 11-desoxycorticosterone that ultimately results in the formation of aldosterone (Curnow et al. 1991, Muller 1998).

Upon binding of ANGII the ANGII receptor type 1 $\left(A_{1}\right)$ couples to the $G_{q}$ protein, which in turn stimulates phospholipase $\mathrm{C}$ to generate the second messengers diacylglycerol (DAG) and inositol triphosphate $\left(\mathrm{IP}_{3}\right)$. DAG and $\mathrm{IP}_{3}$ then activate protein kinase $\mathrm{C}$ (PKC) and liberate intracellular stores of calcium (de Gasparo et al. 2000). The immediate phase of aldosterone stimulation is followed by sustained release, which is dependent on depolarization and activation of T- and L-type $\mathrm{Ca}^{2+}$ channels (Rossier et al. 1996). Increased intracellular calcium levels are followed by activation of the calcium binding protein calmodulin (CaM) by CaM kinase (CaMK) I and/or CAMK IV (Condon et al. 2002). Furthermore, several lines of evidence suggest additional activation of CaMK directly through cAMP dependent effects (Gambaryan et al. 2006). CaMK induced phosphorylation of ATF-1 and CREB and transcriptional activation of NGF1-B and Nurr1 in turn induces promotor activation of Cyp11b2 (Bassett et al. 2004a). An alternate signaling pathway engaged by the $\mathrm{AT}_{1}$ receptor is the phosphorylation and activation of MAPK family members including ERK1/ERK2. Although ANGII induced ERK1/ERK2 activation had been shown to require activation of PKC, it has been recently revealed that these intracellular events can also occur independently (Daniels et al. 2005).

Taken together, transcriptional, translational, and posttranslational regulation of StAR that defines steroid output in steroidogenic tissues and molecular mechanisms that ultimately dictate expression levels of Cyp $11 b 2$ as the final step responsible for aldosterone secretion have been characterized in great detail. However, so far, no study has investigated the transcriptional regulation coincident with aldosterone secretion within minutes of acute stimuli. With the present study, we set out to define immediate transcriptional changes that take place in the adrenal gland upon specific stimulation and suppression experiments modulating aldosterone secretion in vivo.

\section{Materials and methods}

\section{Animals and housing conditions}

All animal studies were performed according to protocols examined and approved by the Regierung von Oberbayern and according to the German Animal Protection Law. Mice were kept in a non-specific pathogen free animal facility at an ambient temperature of $22 \pm 2{ }^{\circ} \mathrm{C}$, (relative humidity $60 \pm 5 \%$ ) and on a
$12 \mathrm{~h}$ light: $12 \mathrm{~h}$ darkness circle. The animals were fed with standard breeding chow (sodium $0.24 \%$, potassium $0.91 \%$; Ssniff R/M-H, Soest, Germany) ad libitum with free access to tap water. The experiments were performed on 12-week-old female $\mathrm{C} 3 \mathrm{HeB} / \mathrm{FeJ}$ wild-type mice ( Jackson Laboratory, Bar Harbour, ME, USA), which were maintained in groups of 6-8 individuals.

\section{Stimulation and suppression tests}

Steroidogenic response and aldosterone secretion was investigated upon specific functional tests. As stimuli, ANGII injection and i.p. sodium load were chosen. Moreover, a control group received a sham injection, in order to investigate potential effects of injection itself on adrenocortical function. For each one of the ANGII, sodium load and sham injection, seven groups of five animals were established. The mice of the first group for each stimulus were euthanized by isoflurane inhalation and decapitation for collection of trunk blood and adrenals under baseline conditions. The mice from the remaining six groups received an i.p. injection of $0.2 \mathrm{nmol}$ ANGII (Fluka, Taufkirchen, Germany; Davisson et al. 2000, Cao et al. 2006), $50 \mu \mathrm{l} / \mathrm{g}$ $\mathrm{NaCl} 0.9 \%$ (B Braun, Melsungen, Germany), or a sham injection without anesthesia. After 10, 20, 30, 40, 60, and 120 min five mice per time point were euthanized by isoflurane inhalation for final blood and adrenal collection. To avoid an increase of the examined parameters induced by blood sampling, this procedure was kept to an interval of $<60 \mathrm{~s}$. All adrenals were immediately cleaned from adjacent tissue using a stereo microscope, snap frozen in liquid nitrogen and stored at $-80^{\circ} \mathrm{C}$ until further processing.

\section{Aldosterone measurement}

Aldosterone was determined with an in-house timeresolved fluorescent immunoassay as recently described in detail (Manolopoulou et al. 2008). In brief, $50 \mu \mathrm{l}$ of each plasma sample were extracted using $2 \mathrm{ml}$ dichloromethane/polyethylene glycol $10000(50 \mathrm{mg} / \mathrm{l})$. The mixture was vortexed and after the two phases separated, the organic phase was removed, transferred to another tube, and left to evaporate overnight. On the following day, samples were reconstituted with pure methanol and assay buffer. After reconstitution, $50 \mu \mathrm{l}$ of each of the samples was pipetted in duplicate onto microtiter plates previously coated with the monoclonal mouse antialdosterone capture antibody (Gomez-Sanchez et al. 1987), along with aldosterone calibrators and controls. Subsequently, biotinylated aldosterone tracer was added into each well (5 pg/well) and the plate was incubated 
Table 1 Primer sequences and annealing temperatures used for real-time PCR

\section{Sequence}

Amplification product

$\beta$-actin (fwd)

$\beta$-actin (rev)

Cyp11b2 (fwd)

Cyp11b2 (rev)

Star (fwd)

Star (rev)

Cyp11a1 (fwd)

Cyp11a1 (rev)

NGF1-B (fwd)

NGF1-B (rev)

Nurr1 (fwd)

Nurr1 (rev)

TCATGAAGTGTACGTGGACATCC
CCTAGAAGCATTTGGGTGGACGATG
CAGGGCCAAGAAACCTACA
ACGAGCATTTTGAAGCACCT
GACCTTGAAAGGCTCAGGAAGAAC
TAGCTGAAGATGGACAGACTTGC
AGGACTTTCCCTGCGCT
GCATCTCGGTAATGTTGG
ATGCCTCCCCTACCAATCTTC
CACCAGTTCCTGGAACTTGGA
TCAGAGCCCACGTCGATT
TAGTCAGGGTTTCCTGGAA

Annealing temperature $\left({ }^{\circ} \mathrm{C}\right)$

56

63

60

53

60

60 overnight at $4{ }^{\circ} \mathrm{C}$. The following day, plates were washed and $200 \mu \mathrm{l}$ per well of Europium labeled streptavidin were added. After 30-min incubation at room temperature, the amount of biotinylated aldosterone bound was measured using a fluorometer (VICTOR3, PerkinElmer, Waltham, MA, USA). Analytical sensitivity of the assay was $8 \mathrm{pg} / \mathrm{ml}$, intra-assay coefficients of variation were at concentrations of 18,34 , and $139 \mathrm{pg} / \mathrm{ml}(7 \cdot 3$, $6 \cdot 3$, and $4.4 \%$ respectively). Inter-assay coefficients were $15 \cdot 2,15 \cdot 1$, and $8 \cdot 0 \%$ respectively.

\section{Real-time PCR}

Both adrenals from each individual animal were combined and homogenized in extraction buffer while still frozen. RNA extraction was performed using the SV Total RNA Isolation System according to the manufacturer's instructions (Promega). For cDNA synthesis $1 \mu \mathrm{g}$ total RNA was reverse transcribed utilizing the reverse transcription system (Promega). Quantification of investigated genes was accomplished using the FastStart DNA MasterPlus SYBR Green I reaction mix in the LightCycler 1.5 (Roche). Real-time PCR conditions were pre-incubation at $95^{\circ} \mathrm{C}$ for $10 \mathrm{~min}$ followed by amplification of 40 cycles at $95^{\circ} \mathrm{C}$ for $10 \mathrm{~s}$, the annealing temperature (primer dependent as given in Table 1) for $5 \mathrm{~s}$, and extension at $72^{\circ} \mathrm{C}$, at which the time is calculated by the product length in bps divided by 25 (Roche). The melting curve analysis was performed between 65 and $95{ }^{\circ} \mathrm{C}\left(0 \cdot 1{ }^{\circ} \mathrm{C} / \mathrm{s}\right)$ to determine the melting temperature of the amplified product and to exclude undesired primer dimers. Furthermore, the products were run on a $1 \%$ agarose gel to verify the amplified product. Quantification was adjusted using the housekeeping gene $\beta$-actin. To facilitate overall comparison of individual real-time experiments, expression levels of the particular genes were set as $100 \%$ for wild-type animals and for each time point expression levels were expressed as $\%$ increase or decrease from baseline levels respectively.

\section{Statistical analysis}

All results are expressed as mean \pm s.E.M. Statistical significance was determined using the Mann-Whitney $U$-test. Statistical significance was defined as $P<0.05$ indicated by asterisks in Figs 1-3.

\section{Results}

\section{Short term stimulation and suppression of aldosterone secretion}

In the control group, aldosterone secretion in animals 10 min after sham injection was significantly higher than under baseline conditions (baseline, $88 \pm 10 \mathrm{pg} / \mathrm{ml}$ versus $10 \mathrm{~min} ; 228 \pm 23 \mathrm{pg} / \mathrm{ml}, P<0 \cdot 005)$. This increase

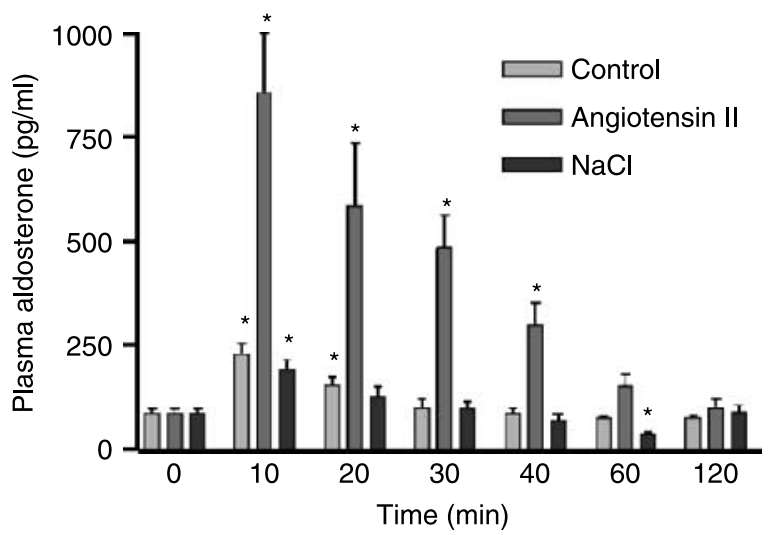

Figure 1 Aldosterone values in control animals after sham injection, after ANGII stimulation and upon $\mathrm{NaCl}$ suppression. Stars denote significant changes over baseline values (i.e., $0 \mathrm{~min}$ ). 


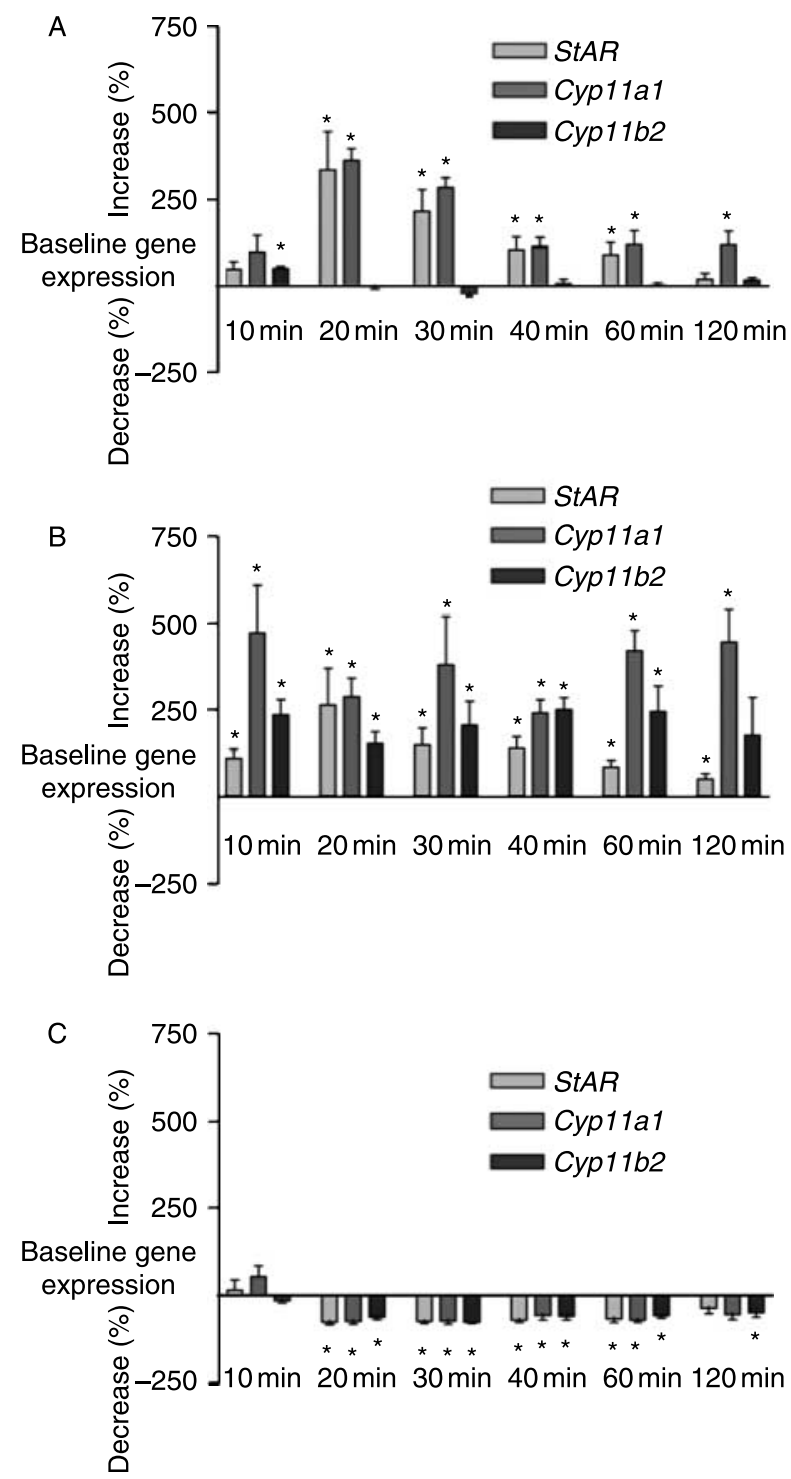

Figure 2 (A) Increase or decrease of the mRNA expression levels of StAR, Cyp11a1, and Cyp11b2 genes in the control group upon sham injection, (B) after ANGIl stimulation, and (C) after $\mathrm{NaCl}$ challenge. Stars denote significant changes for each gene over baseline expression levels which are set as $100 \%$ for each gene.

was still present but less pronounced in the $20 \mathrm{~min}$ sampling $(154 \pm 18 \mathrm{pg} / \mathrm{ml}, P<0.05)$ while at $30 \mathrm{~min}$ and thereafter aldosterone values of sham-treated mice dropped back to levels comparable with baseline values.

Ten minutes after the injection of ANGII, the aldosterone concentration were significantly elevated in comparison with baseline (baseline, $88 \pm 10 \mathrm{pg} / \mathrm{ml}$ versus $10 \mathrm{~min}, \quad 858 \pm 126 \mathrm{pg} / \mathrm{ml}, \quad P<0 \cdot 001)$. The following measurements at 20,30 , and 40 min showed a stepwise reduction while aldosterone secretion still remained significantly higher in comparison with the baseline values $(20 \mathrm{~min}, 585 \pm 133 \mathrm{pg} / \mathrm{ml} ; 30 \mathrm{~min}$, $485 \pm 69 \mathrm{pg} / \mathrm{ml} ; 40 \mathrm{~min}, 297 \pm 48 \mathrm{pg} / \mathrm{ml}, P<0 \cdot 01)$.

After i.p. injection of $1 \mathrm{ml} \mathrm{NaCl} 0.9 \%$, the aldosterone secretion showed a short term increase $(10 \mathrm{~min}$, $192 \pm 20 \mathrm{pg} / \mathrm{ml}, P<0.005)$ comparable with that seen after sham injection. This initial peak was followed by a slow decrease with the lowest aldosterone levels $60 \mathrm{~min}$ after the injection, which were significantly lower in comparison with baseline values $(38 \pm 4 \mathrm{pg} / \mathrm{ml}, P<0 \cdot 005)$.

\section{Short term transcriptional regulation of StAR, Cyp11a1, and aldosterone synthase}

Real-time analysis revealed an increase of StARexpression only after $20 \mathrm{~min}$, the sham injection (expression over baseline: $233 \pm 47 \%, P<0.05)$. This increase was sustained until $60 \mathrm{~min}$ later $(93 \pm 29 \%, P<0 \cdot 05)$ and returned to normal levels after $120 \mathrm{~min}(20 \pm 15 \%$, $P=0 \cdot 31)$. Similarly, Cyp11a1 expression started to increase $20 \mathrm{~min}$ after the sham injection $(363 \pm 31 \%$, $P<0 \cdot 001)$ and did not normalize within the observation period (120 min, $117 \pm 36 \%, P<0 \cdot 05)$. By contrast, Cyp11b2 expression for the animals that received a sham injection revealed only a slight increase over the baseline values $10 \mathrm{~min}$ after the injection $(53 \pm 5 \%, P<0 \cdot 05)$ which came back to baseline expression levels in the 20 min group $(-2 \pm 7 \%, P=0.93)$ and thereafter.

ANGII injection induced an increase in StAR expression already after $10 \mathrm{~min}(111 \pm 22 \%, P<0.05)$ and after a peak at $20 \mathrm{~min}(264 \pm 95 \%, P<0 \cdot 05)$ expression remained elevated until $120 \mathrm{~min}$ later $(51 \pm 14 \%, P<0.05)$. Similarly, Cyp11a1 expression displayed a significant increase already $10 \mathrm{~min}$ after the injection $(474 \pm 121 \%, P<0 \cdot 01)$ and the levels remained significantly elevated over baseline up to 120 min later $(446 \pm 81 \%, P<0.05)$. Furthermore, ANGII injection resulted in a significant increase in Cyp11b2 expression after $10 \min (236 \pm 39 \%, P<0 \cdot 005)$ which was sustained up to $60 \mathrm{~min}$ later $(244 \pm 65 \%$, $P<0 \cdot 01)$. Overall, induction of both StAR and Cyp11a1 expression levels were within a similar range after sham injection and after ANGII stimulation. By contrast, ANGII induced upregulation of $C y p 11 b 2$ expression was significantly higher in comparison with that followed by sham injection $(P<0.01$ for time points $10-60 \mathrm{~min})$.

Both StAR and Cyp11a1 expression was reduced upon sodium challenge between $20 \mathrm{~min}(S t A R,-77 \pm 7 \%$; $P<0.001$, Cyp11a1, $-74 \pm 7 \% ; P<0 \cdot 001)$ and $60 \mathrm{~min}$ $($ StAR, $-68 \pm 9 \% ; \quad P<0.05, \quad$ Cyp11a1, $-72 \pm 7 \%$, $P<0 \cdot 05)$ and Cyp11a1 levels remained low even after 120 min $(-55 \pm 12 \%, P<0 \cdot 05)$. Furthermore, sodium load had significant effects on Cyp11b2 expression levels that remained suppressed between $20 \mathrm{~min}(-63 \pm 6 \%$, $P<0 \cdot 05)$ and $60 \mathrm{~min}(-58 \pm 6 \%, P<0 \cdot 01)$. 

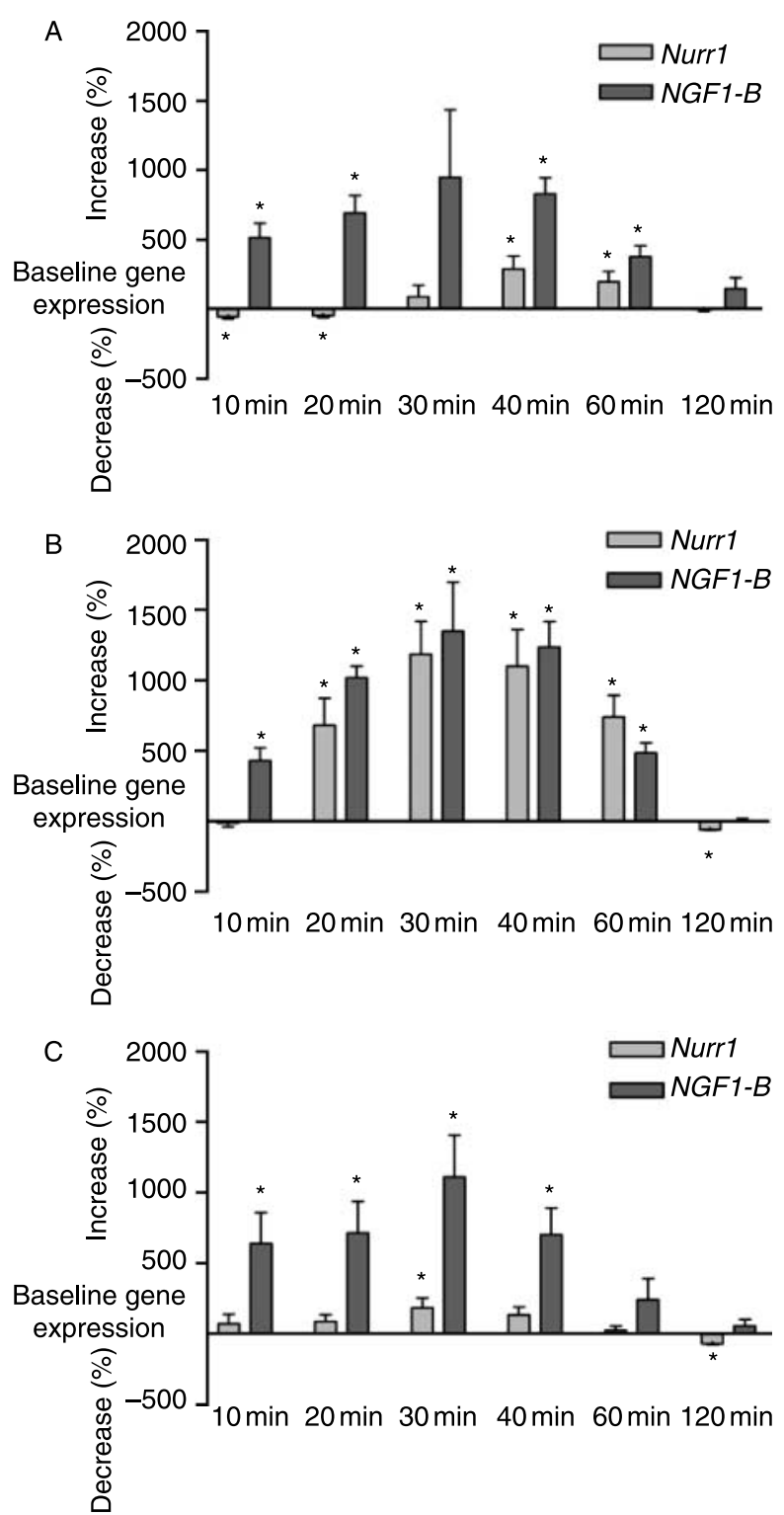

Figure 3 (A) Increase or decrease of the mRNA expression levels of Nurr1 and NGF1-B in the control group upon sham injection, (B) after ANGII stimulation, and (C) after $\mathrm{NaCl}$ challenge. Stars denote significant changes for each gene over baseline expression levels which are set as $100 \%$ for each gene.

\section{Short term transcriptional regulation of NGF1-B and Nurr1}

After sham injection, NGF1-B expression was significantly upregulated already after $10 \min (512 \pm 87 \%$; $P<0 \cdot 001)$ whereas Nurrl expression showed a transient decrease over baseline up to $20 \mathrm{~min}(-48 \pm 13 \%$; $P<0 \cdot 05)$ and subsequently a slight increase $(60 \mathrm{~min}$, $195 \pm 65 \% ; P<0 \cdot 05)$. By contrast, ANGII injection caused a pronounced increase in the expression of both NGF1-B and Nurrl already 20 min after injection
(Nurr1， 682 $\pm 170 \% ; P<0 \cdot 01$, NGF1-B， $1020 \pm 71 \%$; $P<0.001$ ) which lasted up to $60 \mathrm{~min}$ (Nurr1, $740 \pm 136 \% ; P<0 \cdot 005$, NGF1-B, $485 \pm 63 \% ; P<0 \cdot 001$ ). By contrast, 30 min after the sodium load, Nurr1 mRNA displayed a transient increase $(185 \pm 60 \% ; P<0.05)$ and later a progressive decrease with a significant drop under baseline parameters after $120 \mathrm{~min}(-70 \pm 7 \%$; $P<0 \cdot 005)$. NGF1-B expression, however, displayed a constant and significant increase during the first hour (10 min: $641 \pm 192 \%$; $P<0.05,40$ min: $703 \pm 209 \%$; $P=0 \cdot 01)$ similar to those observed after sham and ANGII injection.

\section{Discussion}

Transcriptional activation as well as post-transcriptional modification of steroidogenic enzymes is the major regulatory mechanisms for acute and chronic modulation of adrenocortical steroid production and release (Christenson \& Strauss 2001). In the present study, we investigated aldosterone secretion and concomitant transcriptional regulation of key steroidogenic enzymes and nuclear transcription factors upon short term stimulation and suppression experiments in vivo. Using an in-house developed time-resolved fluorescent immunoassay (Manolopoulou et al. 2008), we demonstrate the expected acute stimulation of aldosterone secretion upon ANGII stimulation and delayed suppression of aldosterone output following sodium challenge. Of note, the handling procedure including i.p. injection was followed by a significant increase in aldosterone levels starting already $10 \mathrm{~min}$ after the procedure. A concomitant increase in expression levels of StAR, Cyp11a1, and of Cyp11b2 was detectable in the adrenals of sham-treated animals. As ACTH is a known stimulator of StAR transcription (Lehoux et al. 1998) and stress-induced activation of the hypothalamuspituitary-adrenal (HPA) axis has been demonstrated to stimulate zona glomerulosa steroidogenesis (Stier et al. 2004), the observed short term increases in injectioninduced aldosterone synthesis are likely to result from endogenous ACTH stimulation. In general, in vivo experiments are prone to unintended side effects induced by stress or by pharmacological inhibition of HPA axis activity which limit the accuracy of experimental endpoints. However, molecular mechanisms that are modulated by complex regulatory interactions between the renin-angiotensin-aldosterone (RAA) system and HPA axis that are also present under physiological conditions can only be studied in the in vivo setting. Notably, stress induced changes in adrenal transcriptional profiles were more pronounced and sustained for StAR and Cyp11a1 while Cyp11b2 expression levels were only significantly elevated over baseline at very early time points. 
ANGII as one of the main stimulator of glomerulosa aldosterone output expectedly induced a fast and pronounced increase in aldosterone levels also in our stimulation experiment. The observed elevation of aldosterone release was accompanied by fast changes in adrenal mRNA levels which were evident already 10 min after the stimulatory event. In contrast to ANGII dependent changes of StAR and Cyp11a1 mRNA levels which were in a similar range than those of shamtreated animals, ANGII-induced upregulation of Cyp11b2 was much more pronounced as compared with sham injection related changes. To our knowledge, regulation of the expression of Cyp11b2 within such a short period of time has not been reported to date. As a general elongation rate of mRNAs has been determined in the range of 18 nucleotides per second (Schafer et al. 1991) detectable upregulation of the investigated steroidogenic enzymes with a transcript size in the range of 855 (StAR), 1503 (Cyp11b2), and 1581 (Cyp11a1) bp is conceivable. However, other mechanisms contributing to the observed changes in mRNA levels such as regulation of RNA stability cannot be excluded.

Intra-peritoneal sodium challenge was followed by an immediate slight increase of aldosterone response similar to that observed after sham injection. While at this earliest time point both StAR and Cyp11a1 showed a trend towards increased expression levels, the steroidogenic enzymes including CYP11b2 dropped below baseline levels at $20 \mathrm{~min}$ and thereafter. This suppression in expression was followed by a delayed reduction in aldosterone secretion at $60 \mathrm{~min}$. It has been demonstrated that StAR is subject to down-regulation by the nuclear factor $D A X-1$ (Stocco 2001) but whether this mechanism is involved in a short term negative regulation as observed in our in vivo model requires further investigations.

In situ hybridization studies in rats have suggested that chronic ANGII stimulation does not increase StAR expression within zona glomerulosa cells, whereas expression of Cyp11b2 was induced (Peters et al. 1998). Thus, regulatory mechanisms are likely to be in place that specifically modify steroidogenic capacity towards mineralocorticoid output. In this context, NGF1-B and Nurrl have been identified as two transcription factors involved in CaMK dependent transcriptional regulation of Cyp11b2 expression. Interestingly, we observed that time-dependent increases of mRNA levels of NGF1-B are comparable between the treatment groups of sham injection, or ANGII and $\mathrm{NaCl}$ administration respectively and, thus, likely to be the result of stress related alterations. By contrast, Nurr1 expression levels only slightly changed during the course of sham injection and sodium load, but were robustly induced upon ANGII administration. Thus, these results provide indirect evidence that among the two transcription factors which have been proposed to be involved in aldosterone secretion, only Nurr1 is likely to have potential impact in short term aldosterone regulation. However, as Nurr1 expression levels are not clearly suppressed upon sodium load, additional regulatory mechanisms must be in place to explain the observed sodium dependent suppression of steroidogenic enzymes.

In accordance with these findings, in vitro studies in H295R human adrenocortical cells have demonstrated an ANGII dependent regulation of Nurrl (Romero et al. 2004). By contrast, NGF1-B has been suggested to preferentially regulate steroid enzyme genes related to cortisol production (Kelly et al. 2004). Furthermore, expression studies in adrenal adenomas have demonstrated higher Nurrl immunoreactivity in aldosteronomas in comparison with Cushing adenomas, whereas NGF1-B immunoreactivity showed no significant differences between the two groups. In addition, an association between the mRNA expression of Nurrl and Cyp11b2 could be observed (Bassett et al. 2004b, Lu et al. 2004).

Taken together, we describe regulation of aldosterone secretion following specific stimulation and suppression paradigms in vivo that are accompanied by short term transcriptional changes of key steroidogenic enzymes and nuclear transcription factors. From the investigated parameters on the mRNA level StAR, Cyp11a1 and NGF1-B appear to respond more to unspecific stress-related effects, whereas Cyp11b2 and Nurr1 are preferentially regulated by specific stimulation of the renin-angiotensin-aldosterone system. In all instances, changes in adrenal mRNA levels were detectable within a short time frame. Overall, the determination of specific pattern of these transcriptional changes will provide the framework for elucidation of molecular mechanisms underlying these physiological changes.

\section{Declaration of interest}

There is no conflict of interest that could be perceived as prejudicing the impartiality of the research reported.

\section{Funding}

This work was supported in part by a grant from the German Academic Exchange Service (A/06/12144) to AS and grant by the GermanIsraeli-Foundation (173-201.4/2006) to FB.

\section{Acknowledgements}

We would like to acknowledge Brigitte Mauracher (Medizinische Klinik Innenstadt, Munich) and Sandra Hoffman (Helmholtz Zentrum, Munich) for their excellent technical assistance. 


\section{References}

Bassett MH, Suzuki T, Sasano H, White PC \& Rainey WE 2004a The orphan nuclear receptors NURR1 and NGFIB regulate adrenal aldosterone production. Molecular Endocrinology 18 279-290.

Bassett MH, White PC \& Rainey WE 2004b A role for the NGFI-B family in adrenal zonation and adrenocortical disease. Endocrine Research 30 567-574.

Black SM, Harikrishna JA, Szklarz GD \& Miller WL 1994 The mitochondrial environment is required for activity of the cholesterol side-chain cleavage enzyme, cytochrome P450scc. PNAS 91 $7247-7251$.

Cao XR, Shi PP, Sigmund RD, Husted RF, Sigmund CD, Williamson RA, Stokes JB \& Yang B 2006 Mice heterozygous for beta-ENaC deletion have defective potassium excretion. American Journal of Physiology. Renal Physiology 291 F107-F115.

Caron KM, Ikeda Y, Soo SC, Stocco DM, Parker KL \& Clark BJ 1997 Characterization of the promoter region of the mouse gene encoding the steroidogenic acute regulatory protein. Molecular Endocrinology 11 138-147.

Christenson LK \& Strauss JF III 2001 Steroidogenic acute regulatory protein: an update on its regulation and mechanism of action. Archives of Medical Research 32 576-586.

Clark BJ, Wells J, King SR \& Stocco DM 1994 The purification, cloning, and expression of a novel luteinizing hormone-induced mitochondrial protein in MA-10 mouse Leydig tumor cells. Characterization of the steroidogenic acute regulatory protein (StAR). Journal of Biological Chemistry 269 28314-28322.

Condon JC, Pezzi V, Drummond BM, Yin S \& Rainey WE 2002 Calmodulin-dependent kinase I regulates adrenal cell expression of aldosterone synthase. Endocrinology 143 3651-3657.

Curnow KM, Tusie-Luna MT, Pascoe L, Natarajan R, Gu JL, Nadler JL \& White PC 1991 The product of the CYP11B2 gene is required for aldosterone biosynthesis in the human adrenal cortex. Molecular Endocrinology 5 1513-1522.

Daniels D, Yee DK, Faulconbridge LF \& Fluharty SJ 2005 Divergent behavioral roles of angiotensin receptor intracellular signaling cascades. Endocrinology 146 5552-5560.

Davisson RL, Oliverio MI, Coffman TM \& Sigmund CD 2000 Divergent functions of angiotensin II receptor isoforms in the brain. Journal of Clinical Investigation 106 103-106.

Ferguson JJ Jr 1963 Protein synthesis and adrenocorticotropin responsiveness. Journal of Biological Chemistry 238 2754-2759.

Gambaryan S, Butt E, Tas P, Smolenski A, Allolio B \& Walter U 2006 Regulation of aldosterone production from zona glomerulosa cells by ANGII and cAMP: evidence for PKA-independent activation of CaMK by cAMP. American Journal of Physiology. Endocrinology and Metabolism 290 E423-E433.

de Gasparo M, Catt KJ, Inagami T, Wright JW \& Unger T 2000 International union of pharmacology. XXIII. The angiotensin II receptors. Pharmacological Reviews 52 415-472.

Gomez-Sanchez CE, Foecking MF, Ferris MW, Chavarri MR, Uribe L \& Gomez-Sanchez EP 1987 The production of monoclonal antibodies against aldosterone. Steroids 49 581-587.

Gummow BM, Scheys JO, Cancelli VR \& Hammer GD 2006 Reciprocal regulation of a glucocorticoid receptor-steroidogenic factor-1 transcription complex on the Dax-1 promoter by glucocorticoids and adrenocorticotropic hormone in the adrenal cortex. Molecular Endocrinology 20 2711-2723.

Hum DW \& Miller WL 1993 Transcriptional regulation of human genes for steroidogenic enzymes. Clinical Chemistry 39 333-340.
Kelly SN, McKenna TJ \& Young LS 2004 Modulation of steroidogenic enzymes by orphan nuclear transcriptional regulation may control diverse production of cortisol and androgens in the human adrenal. Journal of Endocrinology 181 355-365.

Lehoux JG, Fleury A \& Ducharme L 1998 The acute and chronic effects of adrenocorticotropin on the levels of messenger ribonucleic acid and protein of steroidogenic enzymes in rat adrenal in vivo. Endocrinology 139 3913-3922.

Lu L, Suzuki T, Yoshikawa Y, Murakami O, Miki Y, Moriya T, Bassett MH, Rainey WE, Hayashi Y \& Sasano H 2004 Nur-related factor 1 and nerve growth factor-induced clone $\mathrm{B}$ in human adrenal cortex and its disorders. Journal of Clinical Endocrinology and Metabolism 89 4113-4118.

Manolopoulou J, Bielohuby M, Caton SJ, Gomez-Sanchez CE, Renner-Mueller I, Wolf E, Lichtenauer UD, Beuschlein F, Hoeflich A \& Bidlingmaier M 2008 A highly sensitive immunofluorometric assay for the measurement of aldosterone in small sample volumes: validation in mouse serum. Journal of Endocrinology 196 215-224.

Muller J 1998 Regulation of aldosterone biosynthesis: the end of the road? Clinical and Experimental Pharmacology and Physiology 25 S79-S85.

Otis M \& Gallo-Payet N 2007 Role of MAPKs in angiotensin II-induced steroidogenesis in rat glomerulosa cells. Molecular and Cellular Endocrinology 265-266 126-130.

Peters B, Clausmeyer S, Obermuller N, Woyth A, Kranzlin B, Gretz N \& Peters J 1998 Specific regulation of StAR expression in the rat adrenal zona glomerulosa. An in situ hybridization study. Journal of Histochemistry and Cytochemistry 46 1215-1221.

Reinhart AJ, Williams SC \& Stocco DM 1999 Transcriptional regulation of the StAR gene. Molecular and Cellular Endocrinology $\mathbf{1 5}$ 161-169.

Romero DG, Plonczynski M, Vergara GR, Gomez-Sanchez EP \& Gomez-Sanchez CE 2004 Angiotensin II early regulated genes in H295R human adrenocortical cells. Physiological Genomics 19 106-116.

Rossier MF, Burnay MM, Vallotton MB \& Capponi AM 1996 Distinct functions of T- and L-type calcium channels during activation of bovine adrenal glomerulosa cells. Endocrinology 137 4817-4826.

Schafer DA, Gelles J, Sheetz MP \& Landick R 1991 Transcription by single molecules of RNA polymerase observed by light microscopy. Nature 352 444-448.

Spat A \& Hunyady L 2004 Control of aldosterone secretion: a model for convergence in cellular signaling pathways. Physiological Reviews 84 489-539.

Stier CT Jr, Serova LI, Singh G \& Sabban EL 2004 Stress triggered rise in plasma aldosterone is lessened by chronic nicotine infusion. European Journal of Pharmacology 495 167-170.

Stocco DM 2001 StAR protein and the regulation of steroid hormone biosynthesis. Annual Review of Physiology 63 193-213.

Stocco DM \& Clark BJ 1993 The requirement of phosphorylation on a threonine residue in the acute regulation of steroidogenesis in MA10 mouse Leydig cells. Journal of Steroid Biochemistry and Molecular Biology 46 337-347.

Stocco DM, Wang X, Jo Y \& Manna PR 2005 Multiple signaling pathways regulating steroidogenesis and steroidogenic acute regulatory protein expression: more complicated than we thought. Molecular Endocrinology 19 2647-2659.

Received in final form 27 January 2009

Accepted 12 February 2009

Made available online as an Accepted Preprint 12 February 2009 